\title{
Intriguing Differences in the Gas-Phase Dissociation Behavior of Protonated and Deprotonated Gonyautoxin Epimers
}

\author{
Felipe A. Dörr, ${ }^{1}$ Borislav Kovačević, ${ }^{2}$ Zvonimir B. Maksić, ${ }^{2}$ Ernani Pinto, ${ }^{1}$ \\ Dietrich A. Volmer ${ }^{3}$ \\ ${ }^{1}$ Departamento de Análises Clínicas e Toxicológicas, Faculdade de Ciências Farmacêuticas, Universidade de São Paulo, São \\ Paulo, SP, Brazil \\ ${ }^{2}$ Quantum Chemistry Group, Ruđer Bošković Institute, Zagreb, Croatia \\ ${ }^{3}$ Institute of Bioanalytical Chemistry, Department of Chemistry, Saarland University, Campus B2.2, 66123 Saarbrücken, Germany
}

\begin{abstract}
The aim of this study was to investigate the unusual gas-phase dissociation behavior of two epimer pairs of protonated gonyautoxins (GTX) following electrospray ionization in comparison to their deprotonated counterparts. The chemical structures of the investigated GTX1-4 variants vary in their substitution pattern at $\mathrm{N}-1$ and the stereochemical orientation of the hydroxysulfate group at C-11 (11 $\alpha$ for GTX1/2 versus $11 \beta$ for GTX3/4). The direct comparison of mass spectra in positive and negative ion modes illustrated two distinct features: first, an intriguing difference between protonated $11 \alpha$ and $11 \beta$ species, where $11 \alpha$ conformations exhibited almost complete dissociation of $[\mathrm{M}+\mathrm{H}]^{+}$ions via facile $\mathrm{SO}_{3}$ elimination, while $11 \beta$ species remained mostly intact as $\left[\mathrm{M}+\mathrm{H}^{+}\right.$; and second, the lack of such differences for the deprotonated counterparts. In this study, we propose an acid-catalyzed elimination mechanism from density functional theory calculations, initiated by a proton transfer of a guanidinium proton to the hydroxysulfate group with simultaneous $\mathrm{SO}_{3}$ release, which is only possible for the $11 \alpha$ conformation based on intramolecular distances. The same mechanism explains the lack of a comparable $\mathrm{SO}_{3}$ loss in the negative ion mode. CID experiments supported this proposed mechanism for GTX1 and GTX2. Computational modeling of product ions seen in the CID spectra of GTX3 and GTX4 established that the lowest energy dissociation pathway for the $11 \beta$ epimers is elimination of water with the possibility for further $\mathrm{SO}_{3}$ release from the intermediate product. Experimental data for structurally analogous decarbamoyl gonyautoxins confirmed the evidence for the GTX compounds as well as the proposed elimination mechanisms.
\end{abstract}

Key words: Toxins, Gonyautoxins, Paralytic shellfish poisons, Epimers, Electrospray ionization, Collision induced dissociation, Functional density theory

This article is dedicated to the memory of Professor Zvonimir Maksić, who sadly passed away during this project (11/09/1938-27/03/2011).

Electronic supplementary material The online version of this article (doi:10.1007/s13361-011-0223-8) contains supplementary material, which is available to authorized users.

Correspondence to: Dietrich A. Volmer; e-mail: dietrich.volmer@mx. uni-saarland.de

\section{Introduction}

Daralytic shellfish poisons (PSPs) are neurotoxins produced by marine dinoflagellates during harmful algal blooms in the oceans and freshwater cyanobacteria $[1,2]$. Shellfish bioaccumulate these toxins from the algae during grazing, which is of great concern because 
of the PSP's high toxicity in humans after they consume shellfish [3]. PSPs have a multifunctional chemical framework despite their small sizes; they are composed of a tetrahydropurine skeleton to which a five-membered ring is fused, and also possess a unique hydrated ketone structure stabilized by two electron-withdrawing guanidinium moieties (Figure 1). A wide variety of PSP analogs exists from substitutions at N-1 (hydroxyl addition), C-11 (hydroxysulfate addition, gonyautoxin variants), and $\mathrm{N}-21$ (sulfonate addition). Several studies have investigated the mass spectrometric and tandem mass spectrometric (MS/MS) analysis of PSP toxins, mostly by means of electrospray liquid chromatography-mass spectrometry (LC-MS) (e.g., references [4-10]).

We have previously discussed the dissociation behavior of two important PSP toxins in detail; viz., saxitoxin (STX) and neosaxitoxin (NEO) [11, 12]. Both compounds' collision-induced dissociation (CID) spectra exhibited an unusually rich variety and abundance of species due to the large number of functional groups within the small skeletal structures and the two guanidinium moieties per molecule. We proposed the actual dissociation mechanisms of the PSPs after calculation of the proton affinities revealed that protonation took place at the pyrimidine guanidinium moieties of both STX and NEO. Most of the parallel and consecutive dissociation reactions were then rationalized through charge-remote and charge-mediated multiple neutral losses of $\mathrm{H}_{2} \mathrm{O}$, $\mathrm{NH}_{3}, \mathrm{CO}, \mathrm{CO}_{2}, \mathrm{CH}_{2} \mathrm{O}$, and different isocyanate, ketenimine, and diimine species $[11,12]$.

The closely-related gonyautoxins (GTX) exhibit several analogous dissociation reactions [11-13] because of their structural similarity (Figure 1). These well-characterized dissociation reactions are not the focus of the present article, but rather an unusual behavior seen for two epimeric pairs of substituted PSPs, namely gonyautoxins and decarbamoyl gonyautoxins (dcGTX) (Figure 1). The GTX compounds differ from NEO and STX as a result of hydroxysulfate substitution at $\mathrm{C}-11$, which can exist in two stereochemical orientations $(\alpha / \beta$ epimers). A notable difference in the epimers' dissociation behaviors in the gas phase was described by Dell'Aversano et al. [13], who observed unusual fragmentation patterns for the two epimeric pairs of gonyautoxins GTX1/GTX4 and GTX2/GTX3 during electrospray ionization (ESI) LC-MS and MS/MS analysis of the protonated molecules. In the measured full-scan mass spectra, the $[\mathrm{M}+\mathrm{H}]^{+}$ion was the most abundant ion for those gonyautoxins having the $\mathrm{C}-11$ hydroxysulfate group in $\beta$-orientation (GTX3/GTX4), while the $[\mathrm{M}+\mathrm{H}-80]^{+}$ product ion, corresponding to loss of $\mathrm{SO}_{3}$ from the

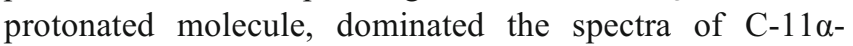
hydroxysulfate toxins (GTX1/GTX2). The authors observed [13] the same pattern in the CID spectra of GTX1-4 and also for decarbamoyl gonyautoxin analogs dcGTX1-4. No mechanistic explanation was given for this observed discrepancy.

The present study investigates these differences of GTX and dcGTX epimers in detail and proposes a mechanism for the gas-phase intramolecular elimination of $\mathrm{SO}_{3}$ from the protonated $11 \alpha$ variants based on density functional theory (DFT). Importantly, as will be shown in this study, the deprotonated GTX epimer pairs do not follow the same trend, which prompted the additional question: why are the protonated $11 \alpha$ species so labile in comparison to their deprotonated anionic counterparts? This paper will also address this question mechanistically.

\section{Experimental}

\section{Chemicals and Standard Solutions}

Reference standard solutions of gonyautoxins GTX1-4 and decarbamoyl gonyautoxins dcGXT2 and dcGTX3 were obtained through the National Research Council/Institute for Marine Biosciences (NRC/IMB)'s Certified Reference Materials Program (CRMP, Halifax, NS, Canada) and were diluted 10 -fold in water $(+0.1 \%$ acetic acid $)$ prior to analysis. Acetonitrile was purchased from J. T. Baker/Avantor (Phillipsburg, NJ, USA). Sigma-Aldrich (St. Louis, MO,
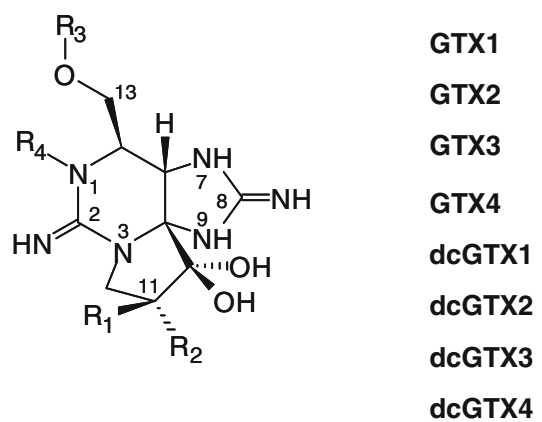

\begin{tabular}{lllll}
$\mathrm{R}_{1}$ & $\mathrm{R}_{2}$ & $\mathrm{R}_{3}$ & $\mathrm{R}_{4}$ & $M_{\mathrm{n}}$ \\
\hline $\mathrm{H}$ & $\mathrm{OSO}_{3} \mathrm{H}$ & $\mathrm{CO}_{2} \mathrm{NH}_{2}$ & $\mathrm{OH}$ & 411 \\
$\mathrm{H}$ & $\mathrm{OSO}_{3} \mathrm{H}$ & $\mathrm{CO}_{2} \mathrm{NH}_{2}$ & $\mathrm{H}$ & 395 \\
$\mathrm{OSO}_{3} \mathrm{H}$ & $\mathrm{H}$ & $\mathrm{CO}_{2} \mathrm{NH}_{2}$ & $\mathrm{H}$ & 395 \\
$\mathrm{OSO} \mathrm{H}$ & $\mathrm{H}$ & $\mathrm{CO}_{2} \mathrm{NH}_{2}$ & $\mathrm{OH}$ & 411 \\
$\mathrm{H}$ & $\mathrm{OSO}_{3} \mathrm{H}$ & $\mathrm{H}$ & $\mathrm{OH}$ & 368 \\
$\mathrm{H}$ & $\mathrm{OSO}_{3} \mathrm{H}$ & $\mathrm{H}$ & $\mathrm{H}$ & 352 \\
OSO $_{3} \mathrm{H}$ & $\mathrm{H}$ & $\mathrm{H}$ & $\mathrm{H}$ & 352 \\
OSO $_{3} \mathrm{H}$ & $\mathrm{H}$ & $\mathrm{H}$ & $\mathrm{OH}$ & 368
\end{tabular}

Figure 1. Chemical structures and nominal molecular weights $\left(M_{\mathrm{n}}\right)$ of the investigated gonyautoxins (GTX) and decarbamoyl gonyautoxins (dcGTX). (GTX1 and GTX2, C-11 $\alpha$-hydroxysulfate; GTX3 and GTX4, C-11 $\beta$-hydroxysulfate.) 
USA) supplied LC-MS grade ammonium formate, acetic acid, formic acid and sodium formate. Organic-free water was generated by a Millipore (Bedford, MA, USA) Direct-Q8 purification system.

\section{Liquid Chromatography}

The epimers GTX1-4 and dcGTX2/dcGTX3 (Figure 1) were separated on a Shimadzu Prominence (Kyoto, Japan) liquid chromatography system using a zic-HILIC column $(150 \times 1.0 \mathrm{~mm}, 3.5 \mu \mathrm{m}$ particles $)$ from Merck Sequant AB (Umeå, Sweden). Separations were achieved by gradient elution using (A) $4 \mathrm{mM}$ ammonium formate $+0.03 \%$ formic acid and (B) acetonitrile/water 90:10 (vol/vol) at $35 \mu \mathrm{L} \cdot \mathrm{min}^{-1}$. Solvent composition was linearly programmed from $50 \% \mathrm{~B}$ to $20 \%$ B within $15 \mathrm{~min}$, held at $20 \%$ B for $5 \mathrm{~min}$, returned to $50 \%$ $\mathrm{B}$ within $1 \mathrm{~min}$, and held for $14 \mathrm{~min}$. The column effluent was directly coupled to the mass spectrometer via electrospray ionization.

\section{Mass Spectrometry}

Electrospray data were acquired on Bruker (Bremen, Germany) MicroTOF-QII quadrupole-time-of-flight (QTOF) and Esquire HCT ion trap mass spectrometers in positive $(-3.5 \mathrm{kV})$ and negative $(+3.5 \mathrm{kV})$ ion modes. The QTOF instrument was operated with the following settings: nebulizer gas, $30 \mathrm{psi}$; drying gas, $4 \mathrm{~L} \cdot \mathrm{min}^{-1}$; drying temperature, $200{ }^{\circ} \mathrm{C}$; collision gas, argon. Collision energy/rf sweeping was activated in the collision cell; 5000 spectra were summed for each data point. The settings for the ion trap instrument were as follows: nebulizer gas, 30 psi; drying gas, $5 \mathrm{~L} \cdot \mathrm{min}^{-1}$; drying temperature, $250{ }^{\circ} \mathrm{C}$; smart ion charge control (ICC), 100,000; maximum accumulation time, $50 \mathrm{~ms}$; MS/MS collision energy optimization (SmartFrag), off. Helium was used as the buffer gas. An isolation width of $4 \mathrm{u}$ was applied in all $\mathrm{MS}^{n}$ experiments. Both instruments were calibrated with a solution of sodium formate $\left(1 \mathrm{mg} \cdot \mathrm{mL}^{-1}\right.$, isopropanol/water 50:50).

\section{Computational Methods}

Density functional theory (DFT) [14] was applied using the Gaussian 03 program package [15]. The search for the BornOppenheimer energy hyper-surfaces was performed using an efficient B3LYP computational scheme [14] employing the $6-31 \mathrm{G}^{*}$ basis set. Energy minima and transition structures were verified by calculating the corresponding Hessian at the same level of theory. For transition structures, intrinsic reaction coordinate (IRC) calculations were performed to confirm that each structure connects minima in both the forward and reverse directions. Higher level single point energies were obtained with BMK/6-311 + G(2df,p). The BMK (Boese-Martin for Kinetics) functional was chosen since it is advocated as the best DFT approach for estimating the barrier heights [16]. Relative energy profiles were calculated using the free energy of the isolated species in the gas phase at $298 \mathrm{~K}$.

\section{Results and Discussion}

As mentioned in the Introduction, the aim of this study was to find answers for two questions raised during the mass spectrometric analysis of GTX epimer pairs in the positive and negative ion modes; viz., what is the exact mechanism of the extensive $\mathrm{SO}_{3}$ elimination from C-11 $\alpha$-hydroxysulfate GTX epimers (GTX1, GTX2) under electrospray ionization conditions when, under the same conditions, their $C-11 \beta$ counterparts (GTX3, GTX4) do not undergo this fragmentation reaction? And, as will be demonstrated below, why are deprotonated molecules of C-11 $\alpha$ epimers much more stable than the protonated species?

To answer these questions, we conducted a first set of experiments where we studied protonated species of the two epimeric pairs of gonyautoxins-GTX1/GTX4 and GTX2/GTX3 - after electrospray ionization. The measured full-scan spectra in the positive and negative modes are illustrated in Figure 2. It is evident from this comparison that $[\mathrm{M}+\mathrm{H}]^{+}$ions of $\mathrm{C}-11 \alpha$ and $\mathrm{C}-11 \beta$ variants differed significantly in their dissociation properties (Figure 2a-d). First, the protonated C-11ß-hydroxysulfate species were much more stable than their corresponding $\mathrm{C}-11 \alpha$ compounds, showing mostly intact $[\mathrm{M}+\mathrm{H}]^{+}$ions. The $[\mathrm{M}+\mathrm{H}]^{+}$ions of the $\mathrm{C}-11 \alpha$ variants, on the other hand, almost completely dissociated into $\left[\mathrm{M}+\mathrm{H}-\mathrm{SO}_{3}\right]^{+}$ions via elimination of neutral $\mathrm{SO}_{3}$ (Figure 2a, c). No analogous $\mathrm{SO}_{3}$ loss reactions were observed for the $\mathrm{C}-11 \beta$ species to a significant extent (Figure 2b, d), confirming the observation of Dell'Aversano et al. [13]. When these experiments were repeated in the negative ion mode, all four GTX species formed stable deprotonated molecules, $[\mathrm{M}-\mathrm{H}]^{-}$at $\mathrm{m} / \mathrm{z} 394$ and 410, respectively (Figure 2e-h).

To elucidate the mechanistic differences for the stabilities and the dissociation reactions of GTX epimers, we conducted density functional theory (DFT) calculations. The most stable conformers of the GTX' $[\mathrm{M}+\mathrm{H}]^{+}$ions in the gas-phase are shown in Figure 3. Close inspection of the three-dimensional structures revealed that for GTX1 and GTX2, the C-11 $\alpha$-hydroxysulfate group is in close proximity to the charge-carrying, protonated guanidine group (Figure 3, right-hand side of the structure). The distances between oxygen of the C-11 $\alpha$-hydroxysulfate group and hydrogen of the protonated guanidine group at $\mathrm{N}-9$ are only $2.105 \AA$ and $2.121 \AA$ for GTX1 and GTX2, respectively (Figure 3). It can also be easily seen from the figure that the C-11ß-hydroxysulfate group is far removed from the guanidinium group for GTX3 and GTX4 (4.310 and 4.291 $\AA)$. Based on the calculated molecule geometries, we are proposing a $\mathrm{SO}_{3}$ elimination mechanism, which is illustrated in Figure 4a. In this reaction, protonated guanidine acts as an acid that readily catalyzes breaking of the $\mathrm{S}-\mathrm{O}$ bond, 

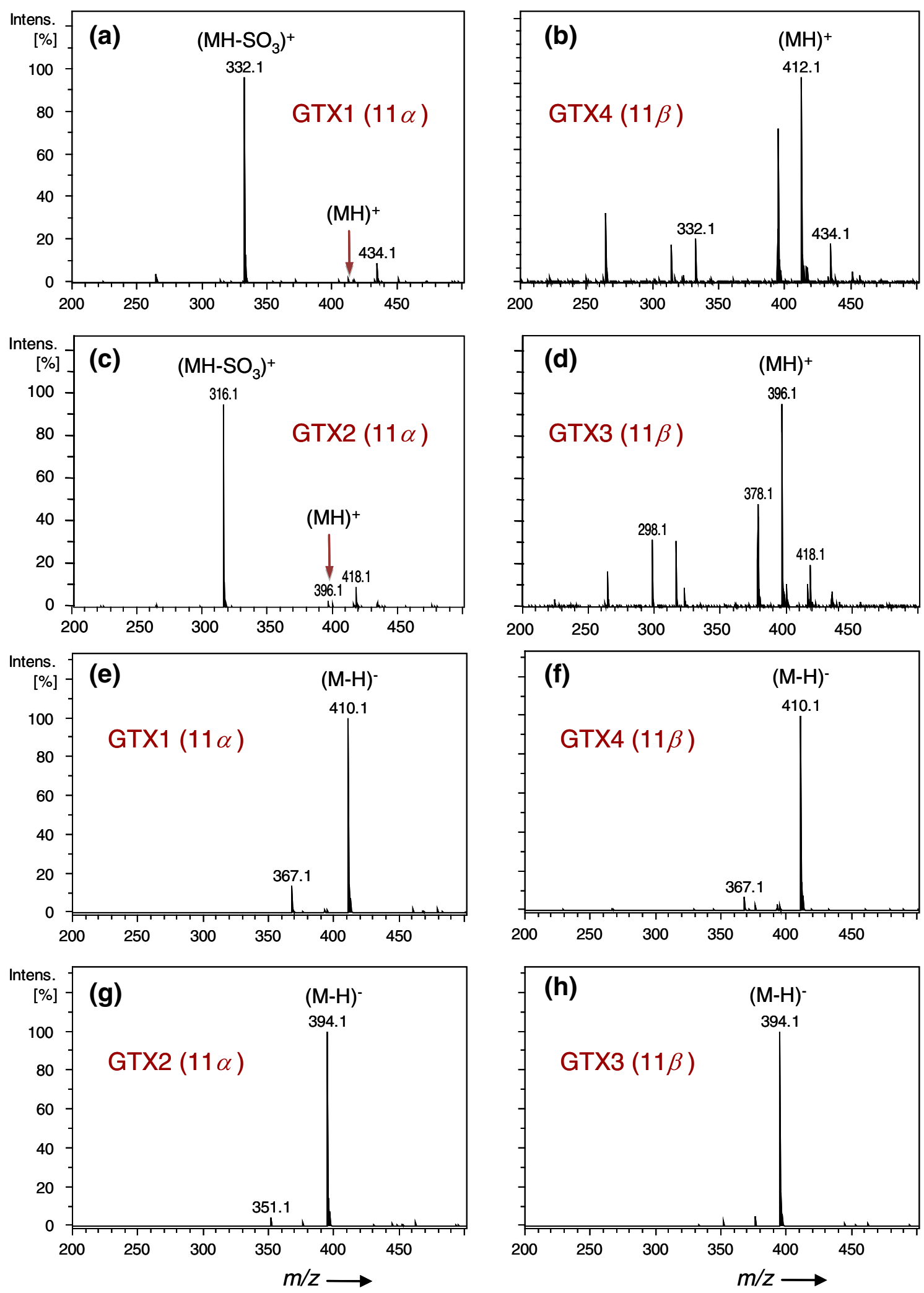

Figure 2. Full-scan mass spectra of GTX variants under positive (a)-(d) and negative (e)-(h) ESI conditions ([M+H $]^{+}$at $m / z 412$ for GTX1, GTX4, $m / z 396$ for GTX 2 and GTX3; [M - H] ${ }^{-}$at $m / z 410$ for GTX1 and GTX4, $m / z$ 394 for GTX2 and GTX3)

followed by elimination of $\mathrm{SO}_{3}$. The second guanidium group on the left-hand side of the molecule does not possess an acidic proton at $\mathrm{N}-1$ or $\mathrm{N}-3$, which could trigger a similar reaction as proposed for the dissociation mechanism. 

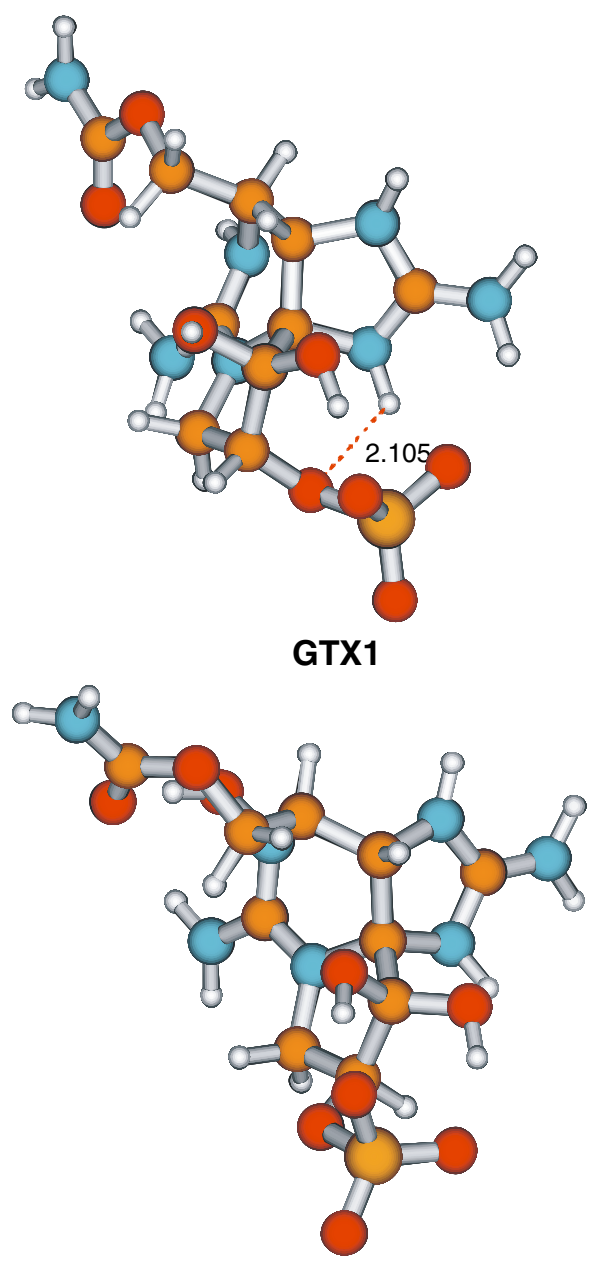

GTX3

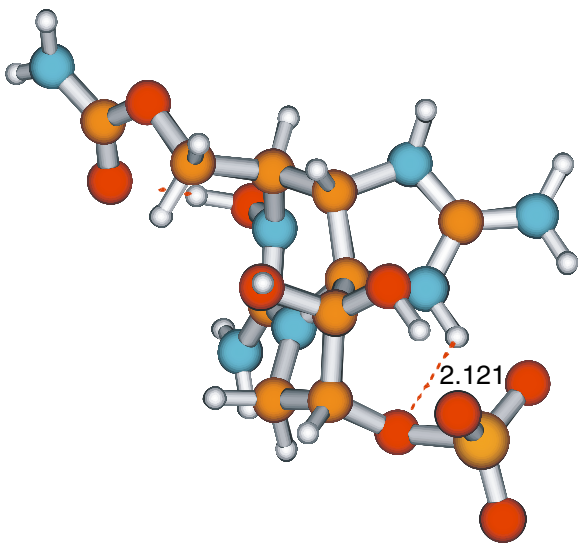

GTX2

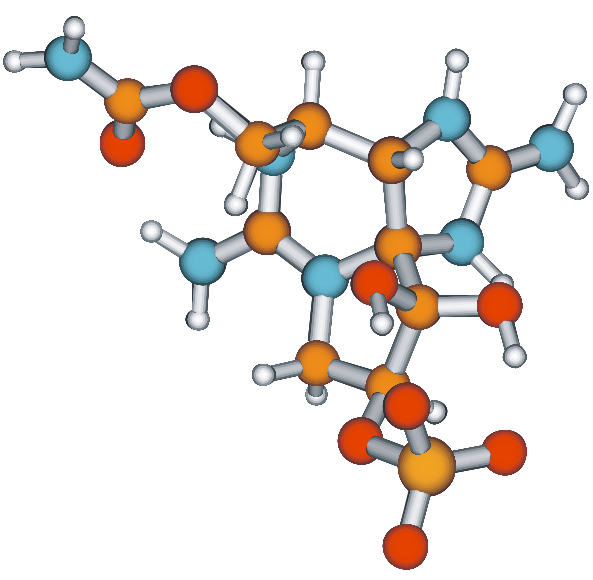

GTX4

Figure 3. The most stable conformers of protonated gonyautoxins GTX1-4 (note: GTX1 and GTX2, C-11 $\alpha$-hydroxysulfate; GTX3 and GTX4, C-11ß-hydroxysulfate). Also shown are calculated hydrogen bond distances between oxygen of the hydroxysulfate group and hydrogen from the guanidinium group for GTX1 and GTX2 (values given in $\AA$.)

The calculated free energy profiles for these dissociation reactions of protonated GTX1 and GTX2 are shown in Figure $4 \mathrm{~b}$ (see Experimental for the theoretical model used). For reasons of simplicity, the structures of the reactant $(R)$, transition state $(T S)$, and product $(P R)$ are presented only for GTX1. The transition state for both ions corresponds to migration of a proton from the protonated guanidinium group to the hydroxysulfate group. After proton transfer, the hydroxysulfate group spontaneously dissociates and forms $\mathrm{SO}_{3}$ and GTX1-OH/GTX2-OH. The calculated reaction barriers for dissociation of GTX1 and GTX2 ions are 56.7 and $54.8 \mathrm{~kJ} \cdot \mathrm{mol}^{-1}$, respectively.

For the C-11 $\beta$-hydroxysulfates (GTX3/GTX4 epimers), the distances of the hydroxysulfate group to the protonated guanidinium groups are much larger (Figure 3), making a comparable dissociation reaction unlikely to occur. DFT calculations confirm that the $\mathrm{SO}_{3}$ group cannot be directly eliminated from these epimers; attempting to cleave the $\mathrm{O}-\mathrm{S}$ bond in the hydroxysulfate group to eliminate $\mathrm{SO}_{3}$, did not result in stable products on the potential energy surface that corresponds to the dissociated system. In this modeling process, the $\mathrm{O}-\mathrm{S}$ distance was gradually raised and for every incremental increase, the energy of the system was calculated. The increase of the distance (elongation of the $\mathrm{O}-\mathrm{S}$ bond) was done purposely, with the system being not relaxed, forcing a certain geometry on it (= potential energy surface scan). In this potential energy scan, dissociation products would be observed if they existed, and approximate barrier heights are then obtained. In our experiments, no dissociation products were seen and we concluded that the process of $\mathrm{SO}_{3}$ elimination does not exist for GTX/GTX4 compounds.

Importantly, the proposed elimination mechanism shown in Figure 4 also explains the stabilities of the deprotonated $11 \alpha$ variants GTX1 and GTX2 in comparison to their protonated counterparts. In our experiments, the deprotonated molecules of all four investigated variants (GTX1-4) exhibited identical behaviors; viz., virtually solitary $[\mathrm{M}-\mathrm{H}]^{-}$ ions were formed during electrospray ionization and no fragmentation reactions, particularly no $\mathrm{SO}_{3}$ eliminations, 
(a)

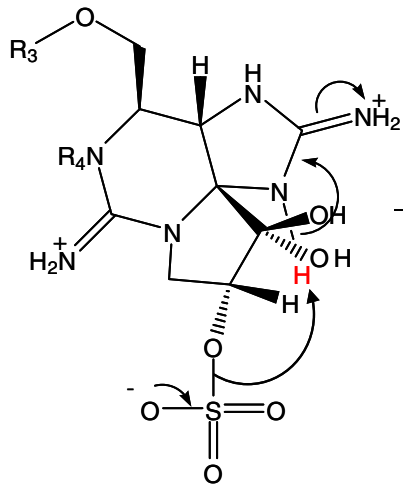

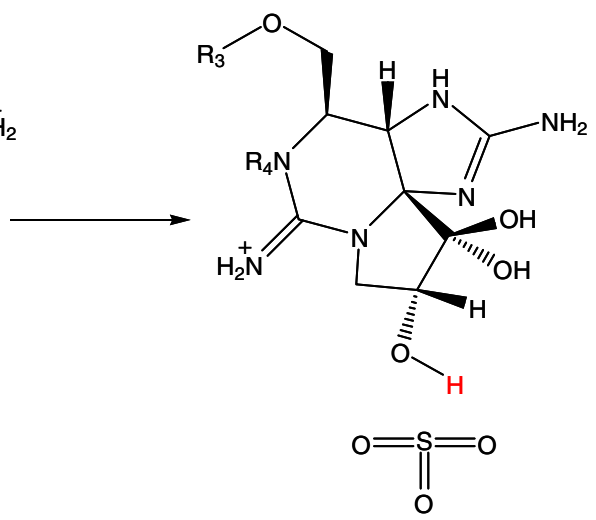

(b)

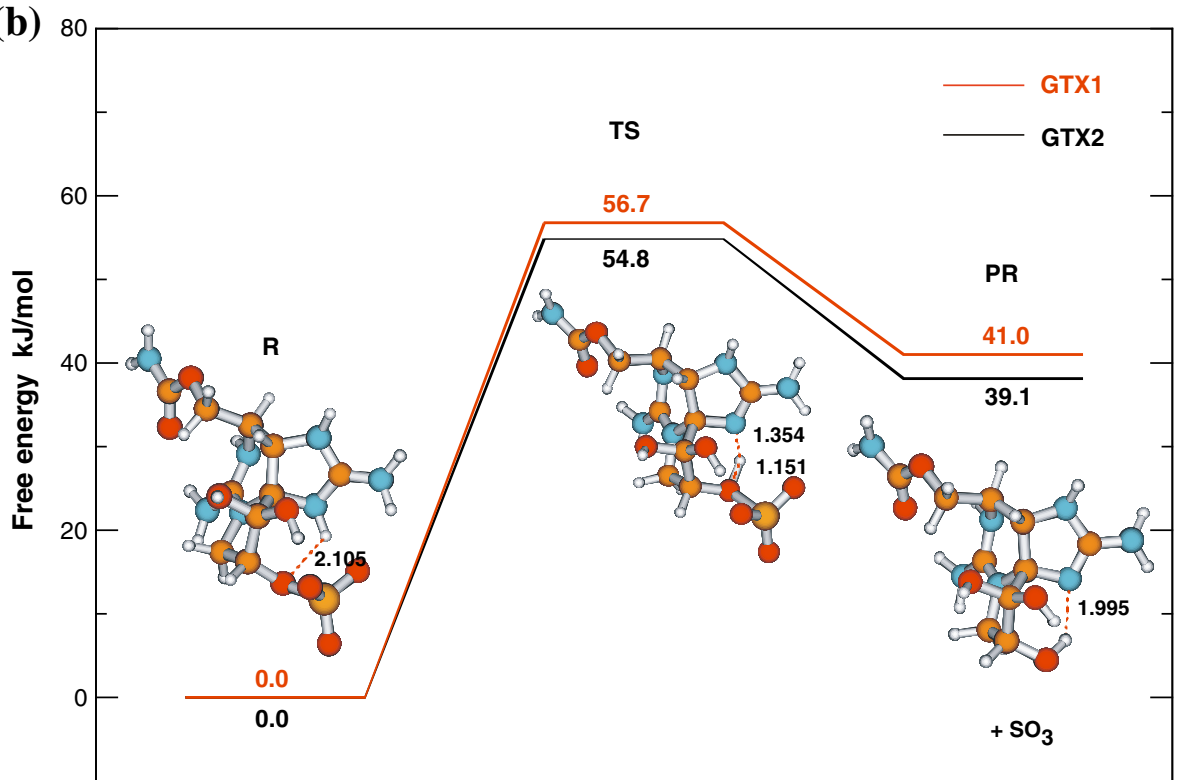

Figure 4. (a) The proposed transition state for the formation of $\left[\mathrm{M}+\mathrm{H}-\mathrm{SO}_{3}\right]^{+}$product ions from protonated GTX1 and GTX2 correspond to migration of a proton (shown in red) from the protonated guanidinium group to the $\mathrm{C}-11$ hydroxysulfate group, followed by spontaneous dissociation of the hydroxysulfate group to form $\mathrm{SO}_{3}$ and GTX1-OH/GTX2-OH. For the GTX3/GTX4 epimers, the distances from the oxygen atom of the hydroxysulfate group to the hydrogen atom of the protonated guanidine group at N-9 are much larger, making comparable dissociation reactions very unlikely to occur. (b) The calculated free energy profile is shown for dissociation of GTX1 (red line) and GTX2 (black line). The structures for the reactant (R), transition state (TS) and product (PR) are shown exemplary for the dissociation of GTX1

were observed (Figure 2e-h). Mechanistically, this can be readily described by the lack of the acidic proton that catalyzes the dissociation reaction shown in Figure 4a, as both GTX1 and GTX2 guanidine groups are neutral in the negative ion mode.

In the second set of experiments, we conducted CID experiments, to support and validate the experimental findings and proposed mechanism. For this, we investigated the dissociation of GTX compounds after collisional activation of the $[\mathrm{M}+\mathrm{H}]^{+}$ions at $\mathrm{m} / z 412$ and 396 for GTX1/GTX4 and GTX2/GTX3, respectively, and the corresponding deprotonated molecules at $\mathrm{m} / \mathrm{z} 410$ and 394. After activation, the protonated $11 \alpha$-hydroxysulfate variants of GTX1 and GTX2 readily eliminated neutral $\mathrm{SO}_{3}$ to give $\left[\mathrm{M}+\mathrm{H}-\mathrm{SO}_{3}\right]^{+}$as virtually sole product ion in the CID spectra (seen at $m / z 332$ and 316 for GTX1 and GTX2, Figure $5 \mathrm{a}, \mathrm{b}$ ), confirming the behavior in the full scan mode (vide supra). When the more stable GTX3 and GTX4 precursor ions of the $11 \beta$ species were made to undergo CID, they produced a more diverse spectrum of product ions, comprising primarily of $\left[\mathrm{M}+\mathrm{H}-\mathrm{H}_{2} \mathrm{O}\right]^{+}$, $\left[\mathrm{M}+\mathrm{H}-\mathrm{SO}_{3}\right]^{+}$, and $\left[\mathrm{M}+\mathrm{H}-\mathrm{H}_{2} \mathrm{O}-\mathrm{SO}_{3}\right]^{+}$ions. Because no comparable $\mathrm{H}_{2} \mathrm{O}$ or combined $\mathrm{H}_{2} \mathrm{O}+\mathrm{SO}_{3}$ losses were seen in the CID spectra of the C-11 $\alpha$-hydroxysulfate species (Figure 6a, b), it was hypothesized that initial $\mathrm{H}_{2} \mathrm{O}$ elimination may provide an intermediate structure that could more easily eliminate $\mathrm{SO}_{3}$ for GTX3 and GTX4, leading to $\left[\mathrm{M}+\mathrm{H}-\mathrm{H}_{2} \mathrm{O}-\mathrm{SO}_{3}\right]^{+}$ions. Direct $\mathrm{SO}_{3}$ elimination from the precursor ions was assumed to be the energetically less favorable route in this hypothesis. 

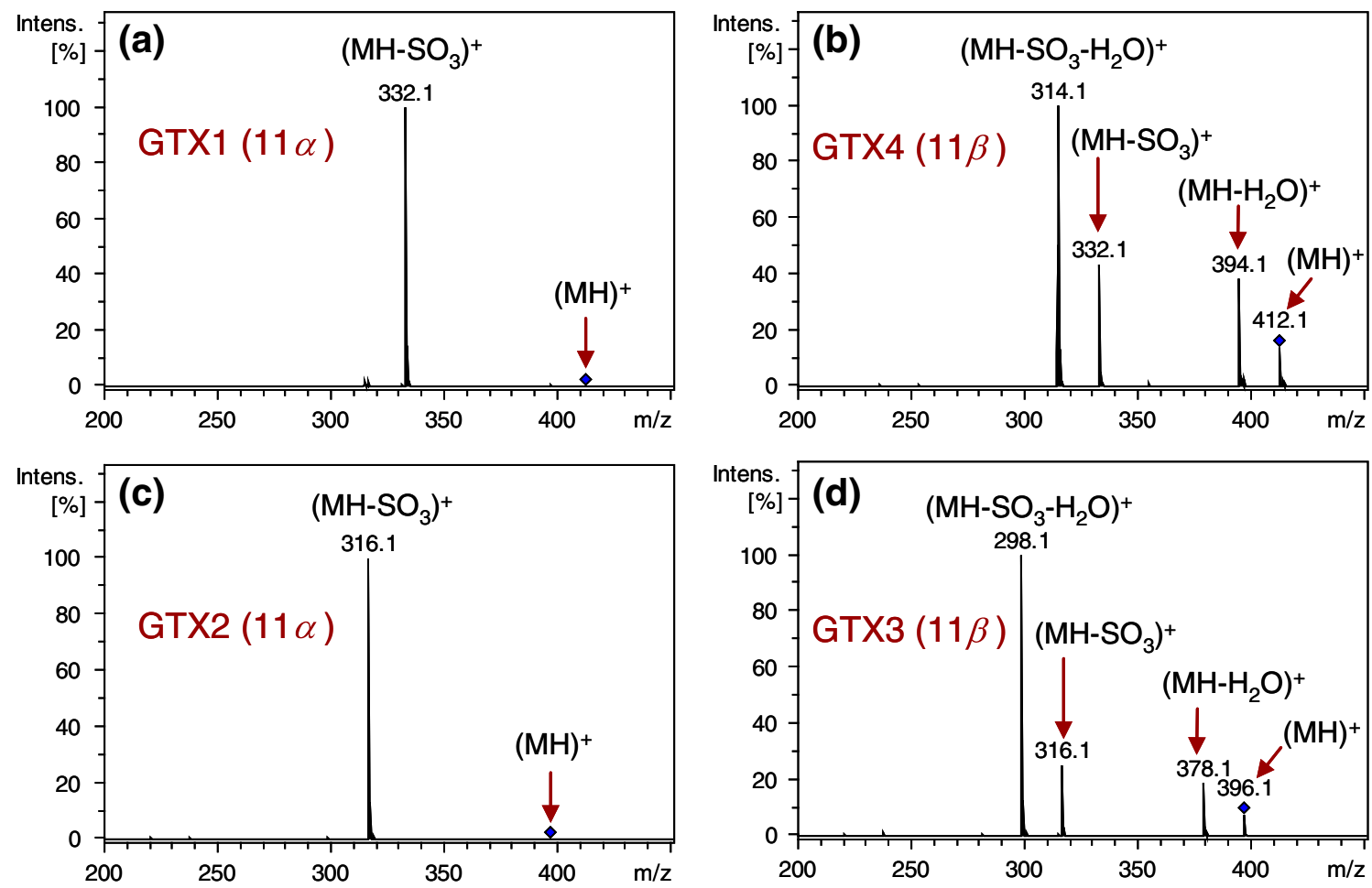

Figure 5. CID spectra of protonated GTX precursor ions: collisional activation of (a), (b) $m / z$ 412, GTX1 and GTX4; (c), (d) $m / z$ 396, GTX2 and GTX3

To further elucidate this mechanistic proposal, we considered the previous results of the DFT calculations (Figure 3). As discussed above, the C-11 hydroxysulfate groups of GTX3 and GTX4 are too far removed from the protonated guanidino group to catalyze elimination of $\mathrm{SO}_{3}$ by the mechanism described in Figure 4. These calculations also revealed, however, that for the GTX3 and GTX4 variants, one of the geminal hydroxyl groups at $\mathrm{C}-12$ is in much closer proximity to the protonated guanidine function than is the case for the corresponding GTX1 and GTX2 compounds (see Figure 3). The distances between the oxygen atom of this hydroxyl group and the hydrogen atom on the protonated guanidine group are $2.127 \AA$ and $2.188 \AA$ for GTX3 and GTX4, whereas distances are much larger for GTX1 and GTX2, $2.936 \AA$ and $2.909 \AA$, respectively. As a result, we are proposing that this $-\mathrm{OH}$ group could be readily protonated by transfer from the guanidinium group. This activated complex then eliminates the protonated hydroxyl group as neutral $\mathrm{H}_{2} \mathrm{O}$ and simultaneously expels $\mathrm{SO}_{3}$. Importantly, for this $\mathrm{SO}_{3}$ expulsion mechanism to work, the C-11 hydroxysulfate group does not have to be in close proximity to the guanidinium function because the proton is transferred via the bridging $-\mathrm{OH}$ group at $\mathrm{C}-12$ (which in turn forms the keto group) to the oxygen atom of the $-\mathrm{OSO}_{3}{ }^{-}$group.

In order to test this hypothesis, a computational study was performed for GTX3 and GTX4, as summarized in Figure 6, which illustrates the mechanism and the energetic profiles along with structures of the transition states. The first step of this mechanism involves proton transfer from the guanidinium group to the hydroxysulfate group. This step actually comprises a double proton transfer, where the hydroxyl group at $\mathrm{C}-12$ acts as a bridge. The proton from the guanidinium group shifts to the hydroxyl group, and, simultaneously, the proton from the hydroxyl group migrates to the hydroxysulfate group (TS1). The reaction barrier for this process is relatively low, $37.6 \mathrm{~kJ} \cdot \mathrm{mol}^{-1}$ for GTX3 and $38.2 \mathrm{~kJ} \cdot \mathrm{mol}^{-1}$ for GTX4. The resulting tautomers are more stable than the precursors GTX3 and GTX4 by amounts of 29.0 and $29.2 \mathrm{~kJ} \cdot \mathrm{mol}^{-1}$. The next step involves the migration of a proton from the hydroxysulfate group to the hydroxyl group, with simultaneous dissociation of the $\mathrm{C}-\mathrm{O}$ bond and elimination of neutral $\mathrm{H}_{2} \mathrm{O}$ (TS2). At the same time, the proton from the second hydroxyl group at $\mathrm{C}-12$ moves to the hydroxysulfate group, which leads to a keto group at $\mathrm{C}-12$ and $\left[\mathrm{M}+\mathrm{H}-\mathrm{H}_{2} \mathrm{O}\right]^{+}$ion formation. The calculated barriers for this process are 50.5 and $51.6 \mathrm{~kJ} \cdot \mathrm{mol}^{-1}$ for GTX3 and GTX4, respectively. In the second stage of our proposal (TS3), the $\left[\mathrm{M}+\mathrm{H}-\mathrm{H}_{2} \mathrm{O}\right]^{+}$product ion would then lose $\mathrm{SO}_{3}$ via $\mathrm{S}-\mathrm{O}$ bond cleavage and proton migration from an oxygen atom of the $\mathrm{SO}_{3}$ group (Figure 6a). The barrier for this $\mathrm{SO}_{3}$ elimination is 130.0 and $129.0 \mathrm{~kJ} \cdot \mathrm{mol}^{-1}$ for $\mathbf{G T X 3}$ and GTX4, respectively. Figure 6a also shows the measured breakdown curve for the $\left[\mathrm{M}+\mathrm{H}\left[^{+}\right.\right.$ion of GTX3 as well as the appearance curves for the $\left[\mathrm{M}+\mathrm{H}-\mathrm{H}_{2} \mathrm{O}\right]^{+}$and $[\mathrm{M}+\mathrm{H}-$ $\left.\mathrm{H}_{2} \mathrm{O}-\mathrm{SO}_{3}\right]^{+}$ions from collisional activation experiments on an ion trap instrument, which are consistent in their energetic 
(a)

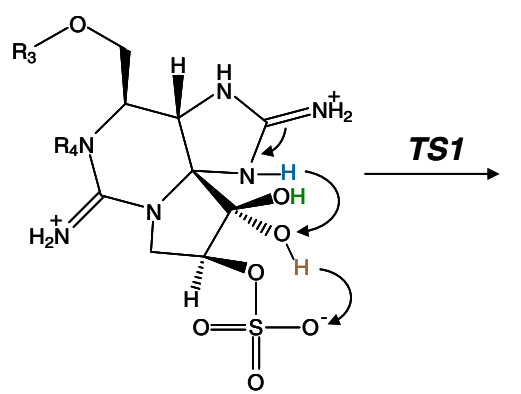

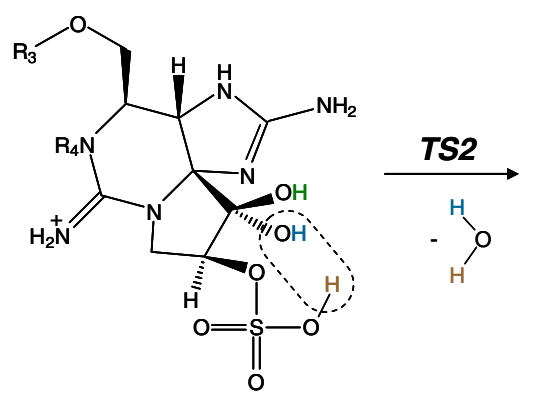

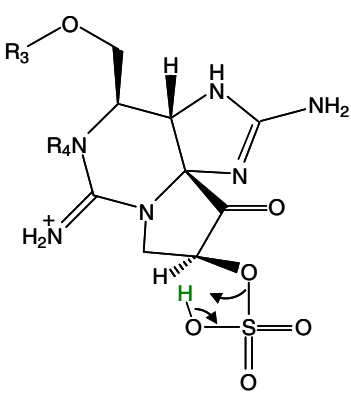<smiles>COC[C@H]1NC(=N)N2C[C@H](O)[C@H](O)[C@@]23NC(N)=N[C@H]13</smiles>

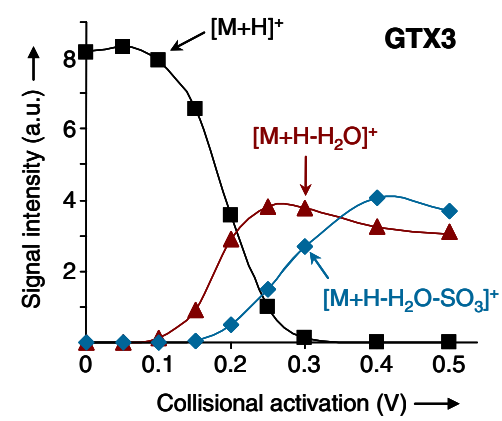

(b)

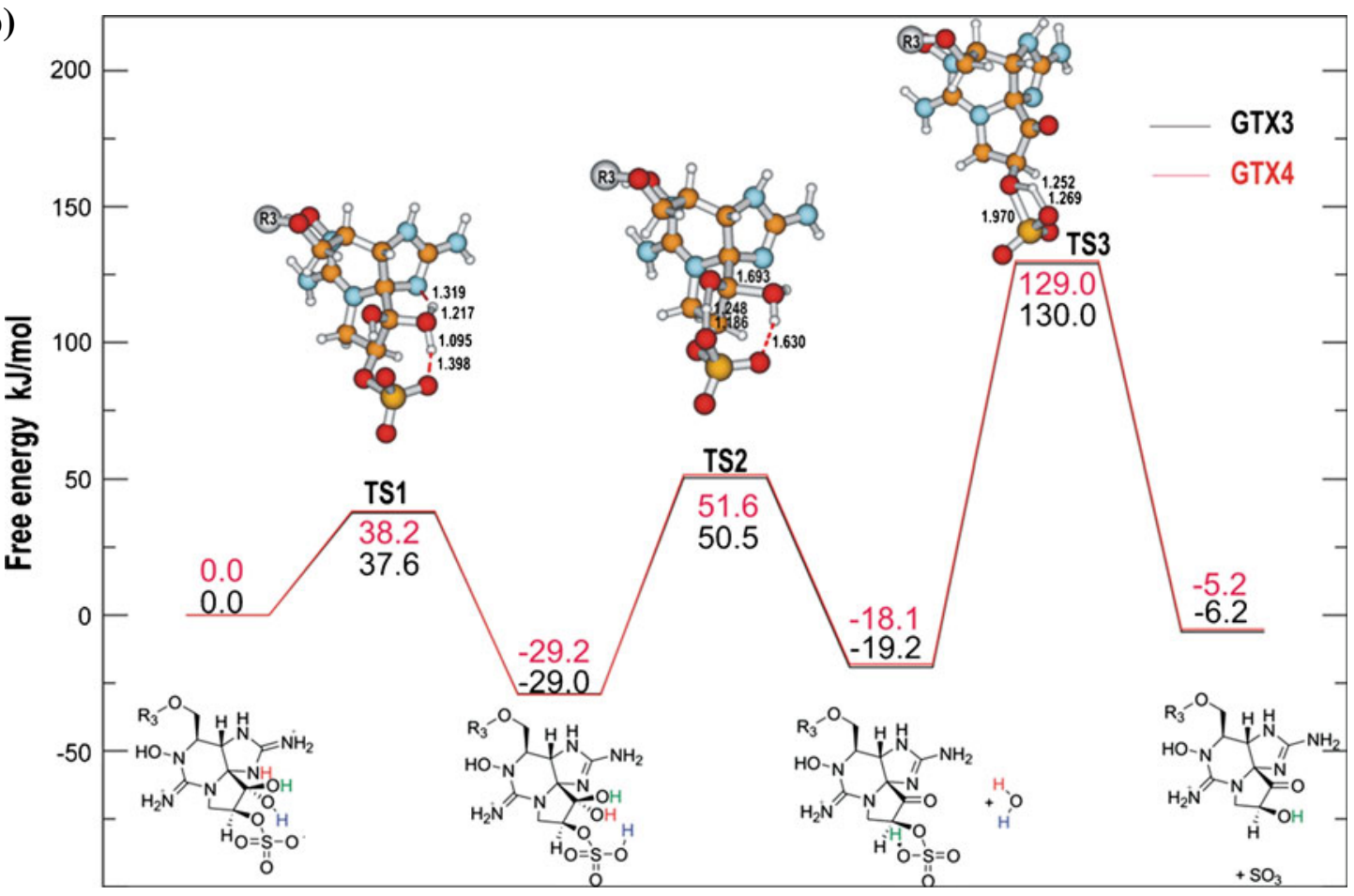

Figure 6. (a) The proposed mechanism for $\mathrm{H}_{2} \mathrm{O}$ and $\mathrm{SO}_{3}$ eliminations from protonated GTX3/GTX4 and measured breakdown and appearance curves for ion species involved in this mechanism (shown for GTX3). (b) Calculated free energy profiles for these reactions. (For reasons of simplicity, only the 3D structures for GTX3 are shown)

requirements with the above proposal (the observed behavior of GTX4 (not shown) was virtually identical to GTX3).

It is important to emphasize that the process of proton transfer $(=T S 1)$ preceding the elimination of water $(=T S 2)$ is energetically less favored for the GTX1 and GTX2 compounds than for GTX3 and GTX4; the calculated reaction barriers TS1 for GTX1 and GTX2 are 89.9 and
$90.4 \mathrm{~kJ} \cdot \mathrm{mol}^{-1}$, respectively. Because the process of $\mathrm{SO}_{3}$ elimination requires significantly less energy (56.7 and $54.8 \mathrm{~kJ} \cdot \mathrm{mol}^{-1}$ ) for GTX1 and GTX2, we conclude that the elimination of water is not a favorable reaction for GTX1 and GTX2, as confirmed by the experimental findings (Figures 2 and 5). These compounds exhibit almost solitary $\mathrm{SO}_{3}$ elimination. 
The CID analysis of the deprotonated molecules of GTX1-4 revealed identical dissociation properties for all molecules, reflecting the uniform behavior in the full scan mode (vide supra). In these analyses, the CID spectra exhibited two major neutral losses from the $[\mathrm{M}-\mathrm{H}]^{-}$ions for all investigated GTX compounds; namely charge-remote neutral losses of $\mathrm{H}_{2} \mathrm{O}$ and isocyanate $\mathrm{NH}=\mathrm{C}=\mathrm{O}(43 \mathrm{Da}$, from residue $\mathrm{R}_{3}$; Figure 1), as reported for other PSP toxins [11]. The CID spectra for the GTX anions are summarized in the Supplementary Material.

Finally, for confirming the observed $11 \alpha / 11 \beta$ differences in the positive ion mode and the uniform behavior of the $11 \alpha / 11 \beta$ negative ions, we also investigated the corresponding decarbamoyl gonyautoxin epimers dcGTX2 and dcGTX3 (Figure 1), which were assumed to show identical behavior to the GTX molecules. As expected, our experiments revealed the same differences and the same trends in the mass spectra for the stereochemical variants, for both positive and negative ions, in full-scan and CID spectra (the mass spectra are summarized in the Supplementary Material).

\section{Conclusions}

In this study, we have compared the stabilities of protonated and deprotonated GTX compounds after electrospray ionization as well as collision-induced dissociation. Inspection of the full-scan spectra of epimers of GTX highlighted two distinct features: first, a notable difference between protonated $11 \alpha-($ GTX1/GTX2) and 11 $\beta$ - (GTX3/4) hydroxysulfate species, where the $11 \alpha$ conformations exhibited an almost complete dissociation of the $[\mathrm{M}+\mathrm{H}]^{+}$ions via facile $\mathrm{SO}_{3}$ elimination but the $11 \beta$ species remained mostly intact. Second, a complete lack of such dissociations for the deprotonated counterparts was observed. An intramolecular, acid-catalyzed elimination mechanism for the protonated $11 \alpha$ compounds was proposed based on density functional theory calculations, which comprised proton transfer of a guanidinium proton to the hydroxysulfate group with simultaneous $\mathrm{SO}_{3}$ release, which is only possible for the $11 \alpha$ conformation. The same mechanism was used to explain the lack of a comparable $\mathrm{SO}_{3}$ loss in the negative ion mode and the greater stabilities of the anions. CID experiments supported this proposed mechanism for GTX1 and GTX2. Computational modeling of the product ions seen in the CID spectra of GTX3 and GTX4 established that the lowest energy dissociation pathway for the $11 \beta$ epimers is elimination of neutral water with the possibility for further $\mathrm{SO}_{3}$ release from the intermediate product.

Importantly, the findings shown in this study have direct implications for the trace analysis of PSP toxins in environmental samples, where most scientists use the positive ion mode for detection. GTX analogs can be analyzed in the negative ion mode with similar detection sensitivity compared with the positive ion mode, but with the advantage of stable deprotonated molecule ions of the precursor ions during electrospray ionization. Structure diagnostic product ions for sensitive MRM can be readily generated by CID. We are currently applying the negative ion mode in quantitative analyses of GTX compounds in environmental samples, the results of which will be reported in a subsequent paper.

\section{Acknowledgments}

The authors thank Fundação de Amparo à Pesquisa do Estado de São Paulo, Coordenação de Aperfeiçoamento de Pessoal de Nível Superior and Conselho Nacional de Desenvolvimento Científico e Tecnológico for financial support. B.K. thanks the Computing Centre of the University of Zagreb (SRCE) for computational time on the ISABELLA cluster. D.A.V. acknowledges research support by the Alfried Krupp von Bohlen und Halbach Stiftung.

\section{References}

1. Luckas, B.: Phycotoxins in Seafood-Toxicological and Chromatographic Aspects. J. Chromatogr. 624, 439-456 (1992)

2. Hallegraeff, G.M.: A Review of Harmful Algal Blooms and Their Apparent Global Increase. Phycologia 32, 79-99 (1993)

3. Van Egmond, H.P., Aune, T., Lassus, P., Speijers, G.J.A., Waldock, M.: Paralytic and Diarrhetic Shellfish Poisons. Occurrence in Europe, Toxicity, Analysis, and Regulation. J. Nat. Toxins 2, 41-83 (1993)

4. Quilliam, M.A.: The Role of Chromatography in the Hunt for Red Tide Toxins. J. Chromatogr. A 1000, 527-548 (2003)

5. Thibault, P., Pleasance, S., Laycock, M.: Analysis of Paralytic Shellfish Poisons by Capillary Electrophoresis. J. Chromatogr. 542, 483-501 (1991)

6. Quilliam, M.A., Janecek, M., Lawrence, J.F.: Characterization of the Oxidation Products of Paralytic Shellfish Poisoning Toxins by Liquid Chromatography-Mass Spectrometry. Rapid Commun. Mass Spectrom. 7, 482-487 (1993)

7. Dahlmann, J., Budakoswski, W.R., Luckas, B.: Liquid Chromatography-Electrospray Ionization Mass Spectrometry Based Methods for the Simultaneous Determination of Algal and Cyanobacterial Toxins in Phytoplankton from Marine Waters and Lakes Followed by Tentative Structural Elucidation of Microcystins. J. Chromatogr. A 994, 45-57 (2003)

8. Arakawa, O., Noguchi, T., Shida, Y., Onoue, Y.: Occurrence of Carbamoyl- $N$-Hydroxy Derivatives of Saxitoxin and Neosaxitoxin in a Xanthid Crab Zosimus aeneus. Toxicon 32, 175-183 (1994)

9. Pleasance, S., Thibault, P., Kelly, J.: Comparison of Liquid-Junction and Coaxial Interfaces for Capillary Electrophoresis-Mass Spectrometry with Application to Compounds of Concern to the Aquaculture Industry. J. Chromatogr. 591, 325-339 (1992)

10. Johnson, R.C., Zhou, Y., Statler, K., Thomas, J., Cox, F., Hall, S., Barr, J.R.: Quantification of Saxitoxin and Neosaxitoxin in Human Urine Utilizing Isotope Dilution Tandem Mass Spectrometry. J. Anal. Toxicol. 33, 8-14 (2009)

11. Sleno, L., Volmer, D.A., Kovačević, B., Maksić, Z.B.: Gas-phase Dissociation Reactions of Protonated Saxitoxin and Neosaxitoxin. $J$. Am. Soc. Mass Spectrom. 15, 462-477 (2004)

12. Sleno, L., Volmer, D.A., Marshall, A.G.: Assigning Product Ions from Complex MS/MS Spectra: The Importance of Mass Uncertainty and Resolving Power. J. Am. Soc. Mass Spectrom. 16, 183-198 (2005)

13. Dell'Aversano, C., Hess, P., Quilliam, M.A.: Hydrophilic Interaction Liquid Chromatography-Mass Spectrometry for the Analysis of Paralytic Shellfish Poisoning (PSP) Toxins. J. Chromatogr. A 1081, 190201 (2005)

14. Koch, W, Holthausen, M.C.: A Chemist's Guide to Density Functional Theory. Wiley-VCH, Weinheim/New York (2000).

15. Frisch, M.J., Trucks, G.W., Schlegel, H.B., Scuseria, G.E., Robb, M.A., Cheeseman, J.R., Montgomery, J.A. Jr., Vreven, T., Kudin, K.N., Burant, J.C., Millam, J.M., Iyengar, S.S., Tomasi, J., Barone, V., Mennucci, B., Cossi, M., Scalmani, G., Rega, N., Petersson, G.A., Nakatsuji, H., Hada, M., Ehara, M., Toyota, K., Fukuda, R., Hasegawa, 
J., Ishida, M., Nakajima, T., Honda, Y., Kitao, O., Nakai, H., Klene, M., Li, X., Knox, J.E., Hratchian, H.P., Cross, J.B., Bakken, V., Adamo, C., Jaramillo, J., Gomperts, R., Stratmann, R.E., Yazyev, O., Austin, A.J., Cammi, R., Pomelli, C., Ochterski, J.W., Ayala, P.Y., Morokuma, K., Voth, G.A., Salvador, P., Dannenberg, J.J., Zakrzewski, V.G.,

Dapprich, S., Daniels, A.D., Strain, M.C., Farkas, O., Malick, D.K., Rabuck, A.D., Raghavachari, K., Foresman, J.B., Ortiz, J.V., Cui, Q., Baboul, A.G., Clifford, S., Cioslowski, J., Stefanov, B.B., Liu, G.,
Liashenko, A., Piskorz, P., Komaromi, I., Martin, R.L., Fox, D.J., Keith, T., Al-Laham, M.A., Peng, C.Y., Nanayakkara, A., Challacombe, M., Gill, P.M.W., Johnson, B., Chen, W., Wong, M.W., Gonzalez, C., Pople, J.A.: Gaussian 03, Revision E.01. Gaussian, Inc., Wallingford CT (2004)

16. Boese, A.D.; Martin, J.M.L.: Development of Density Functionals for Thermochemical Kinetics. J. Chem. Phys. 121, 3405-3416 (2004) 